\title{
Prenatal diagnosis of congenital adrenal hyperplasia: reliability of amniotic fluid steroid analysis
}

\author{
I A HUGHES*, J DYAS $\dagger$, D RIAD-FAHMY†, AND K M LAURENCE* \\ From * the Department of Child Health and + The Tenovus Institute, University of Wales College of Medicine,
} Heath Park, Cardiff CF4 $4 X N$.

SUMMARY The concentration of $170 \mathrm{H}$-progesterone was measured in amniotic fluid samples collected from 55 mothers who had previously had a child with congenital adrenal hyperplasia in due to 21-hydroxylase deficiency. In eight pregnancies the levels of $170 \mathrm{H}$-progesterone were raised; the parents elected to terminate in four and examinations of the fetus confirmed the $\dot{\omega}$ diagnosis of congenital adrenal hyperplasia. In each case, the affected sib was a salt loser. The

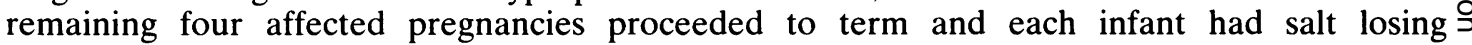
21-hydroxylase deficiency. All 47 infants predicted to be unaffected were normal at birth. However, an increased plasma concentration of $170 \mathrm{H}$-progesterone was documented in a male non-salt loser at three months of age.

Prenatal diagnosis of congenital adrenal hyperplasia by amniotic fluid steroid analysis is $\vec{\varnothing}$ reliable only for the salt losing variant of 21-hydroxylase deficiency. Of the affected sibs in this. study, $20 \%$ died during infancy in a salt losing crisis. This simple and rapid prenatal test is sufficiently reliable to predict the group of infants most at risk in early infancy.

Congenital adrenal hyperplasia is an autosomal recessive disorder of steroid biosynthesis due to deficiency of the enzyme 21-hydroxylase in more than $90 \%$ of cases. ${ }^{1}$ The increased concentration of $170 \mathrm{H}$-progesterone in the blood provides a rapid and reliable test for the disorder at birth. ${ }^{23}$ The fetal adrenal gland synthesises steroids from early gestation $^{4}$; consequently the prenatal diagnosis of congenital adrenal hyperplasia can be established in pregnancies at risk by measurement of increased concentrations of $170 \mathrm{H}$-progesterone in amniotic fluid. $^{5-9}$

The majority of patients with congenital adrenal hyperplasia are salt losers due to a deficiency in both glucocorticoid and mineralocorticoid biosynthesis. The remainder are classified as either simple virilisers, late onset, and cryptic or non-classical cases. ${ }^{10}$ A recent review of published cases detected prenatally suggested that only the salt losing variant was identified by an increased concentration of $170 \mathrm{H}-$ progesterone in amniotic fluid. ${ }^{11}$ We report our experience with the use of this test in a large number of pregnancies at risk of fetal 21-hydroxylase deficiency. The results are reviewed in relation to

Received for publication 24 August 1986

Revised version accepted for publication 24 October 1986 details of the affected sibs (index cases) and the outcome of the pregnancies at risk.

\section{Patients}

A total of 55 pregnancies in 52 mothers who already had children with congenital adrenal hyperplasia was studied. One mother was tested during two andọ another during three consecutive pregnancies. $\frac{5}{3}$ Amniocentesis was performed between 14 and 19. weeks' gestation. A further 96 amniotic fluid sam- $ᄋ$ ples collected from pregnancies at risk for fetal 2 chromosomal abnormalities or neural tube defects은 but with a normal outcome were analysed to $\supset$ determine a concentration range for $170 \mathrm{H}-$ 을. progesterone. Levels of this steroid remain constant between 14 and 20 weeks in maternal serum ${ }^{12}$ and $^{\circ}$ amniotic fluid. ${ }^{6}$ Furthermore, there is no correlation ${ }^{N}$ between the concentration of $170 \mathrm{H}$-progesterone in $N$ samples of maternal serum and amniotic fluido collected simultaneously. ${ }^{6}$

Gestational age was calculated from the date of the last menstrual period and confirmed by:? measurement of the fetal biparietal diameter. Each family received genetic counselling before amniocentesis. Details were recorded about the outcome of pregnancies tested and about the $\mathbb{Q}_{0}^{\mathbb{D}}$ affected sibs. These included sex, the appearance of 


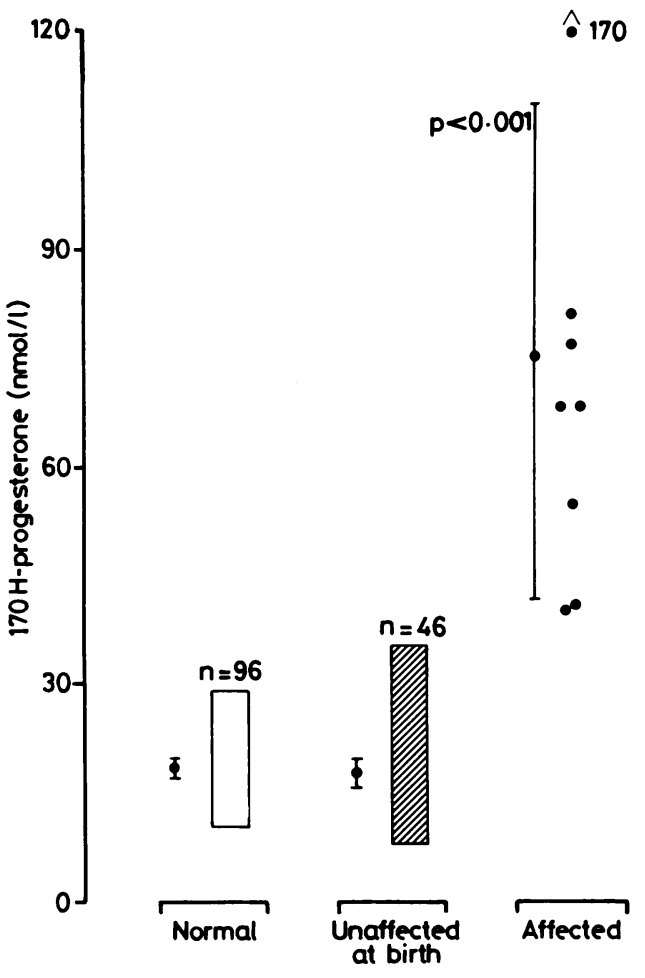

FIG 1 Mean concentration of $170 H$-progesterone (and $95 \%$ confidence intervals) in amniotic fluid from normal pregnancies and from pregnancies at risk for fetal 21-hydroxylase deficiency. The amniotic fluid was collected during the second trimester. the genitalia, and whether the infant or child was a salt loser.

\section{Methods}

Amniotic fluid supernatants were stored at $-20{ }^{\circ} \mathrm{C}$ until analysed. The $170 \mathrm{H}$-progesterone concentration was determined by radioimmunoassay using an ${ }^{125}$ I-radioligand and a magnetisable solid phase antiserum. ${ }^{13}$ Progesterone showed $6 \%$ cross reactivity with a $170 \mathrm{H}$-progesterone antiserum. The sensitivity of the assay was $0.8 \mathrm{nmol} / \mathrm{l}$; the within and between assay coefficients of variation of high, medium, and low quality control samples did not exceed $10 \%$. The data were calculated as means and standard deviation (SD) and expressed with $95 \%$ confidence intervals. Group results were compared by the unpaired Student's $t$ test.

\section{Results}

AMNIOTIC FLUID STEROID ANALYSIS

The concentration of $170 \mathrm{H}$-progesterone in all amniotic fluid samples analysed is shown in fig 1 . The results from pregnancies at risk for fetal 21-hydroxylase deficiency were classified according to known pregnancy outcome.

The mean concentration of $170 \mathrm{H}$-progesterone in second trimester amniotic fluid from normal pregnancies was $18.5 \mathrm{nmol} / \mathrm{l}(5 \cdot 2 \mathrm{SD})$. In 47 term pregnancies at risk with normal infants at birth, there was no significant difference in mean amniotic fluid $170 \mathrm{H}$-progesterone concentration $(17 \cdot 1 \mathrm{nmol} / \mathrm{l}$, $6 \cdot 3 \mathrm{SD}, \mathrm{p}>0 \cdot 1)$. There was a significant increase $(p<0 \cdot 001)$ in mean $170 \mathrm{H}$-progesterone concentration in amniotic fluid from known affected pregnancies

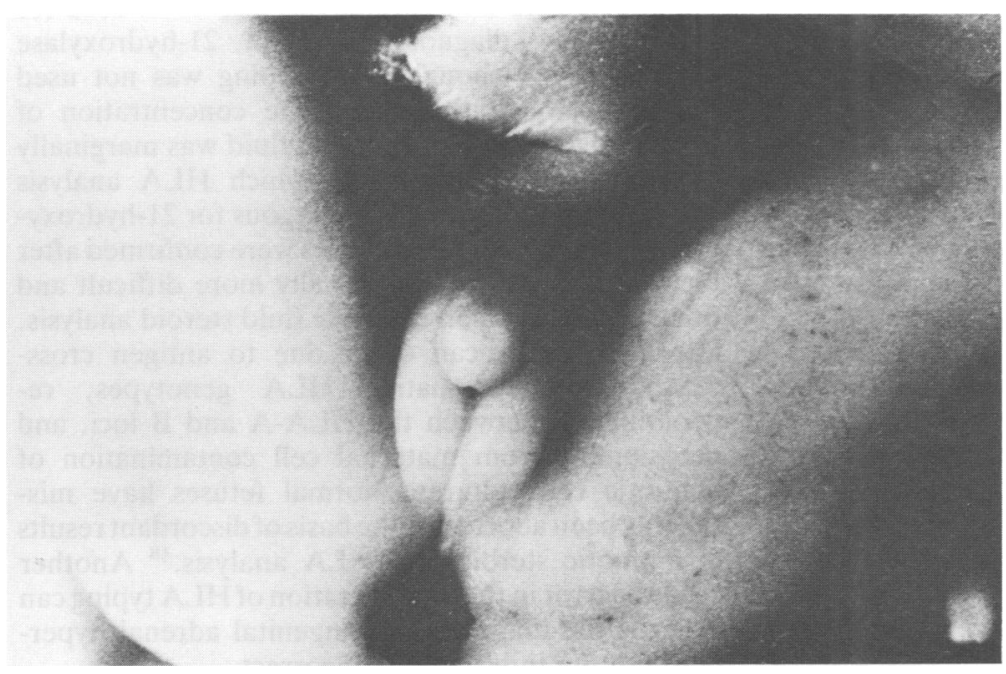

FIG 2 Appearance of the external genitalia of a female fetus with 21-hydroxylase deficiency. There is clitoromegaly and fusion of the labia. 
$(76.0 \mathrm{nmol} / \mathrm{l}, 44.5 \mathrm{SD})$. Individual values ranged from 40 to $170 \mathrm{nmol} / \mathrm{l}$.

OUTCOME OF PREGNANCIES TESTED

Four of the eight affected pregnancies were terminated before 20 weeks' gestation at the request of the parents. All three female fetuses showed evidence of virilisation with fused labia and a single urogenital opening at the base of an enlarged clitoris (fig 2). The external genitalia of the affected male fetus were normal but the combined weight of the adrenal glands $(2.4 \mathrm{~g})$ was increased for gestational age (in normals, the mean combined weight is $1.2 \mathrm{~g}$ with $95 \%$ confidence intervals of 0.6 to $1.7 \mathrm{~g}$ ). ${ }^{14}$ HLA typing of amniotic cells was identical to the haplotype in the affected sib and concurred with a raised $170 \mathrm{H}$-progesterone concentration $(55 \mathrm{nmol} / \mathrm{l})$.

The remaining four pregnancies proceeded to term. A male infant was delivered in each case and 21-hydroxylase deficiency was confirmed by a raised plasma $170 \mathrm{H}$-progesterone concentration. The pattern of plasma electrolyte concentrations was consistent with each infant being a salt loser. A male infant, one of the 47 infants normal at birth, was investigated at three months of age because of scrotal pigmentation. The diagnosis of congenital adrenal hyperplasia was confirmed by increased plasma concentrations of $170 \mathrm{H}$-progesterone and testosterone. He was a non-salt loser, as was his affected sib.

\section{AFFECTED SIBS}

Details were available on 44 affected sibs (index cases) with congenital adrenal hyperplasia, as summarised in the table. The majority were female and $77 \%$ of the total were salt losers. Nine of these ( $20 \%$ of all index cases in this series) had died in infancy during an episode of acute adrenal insufficiency. There were no reported deaths in non-salt losers.

\section{Discussion}

This study extends our previous observations on the value of amniotic fluid $170 \mathrm{H}$-progesterone measurements for the prenatal diagnosis of congenital adrenal hyperplasia. ${ }^{79}$ The assay is simple and results are available within two hours of receipt of

TABLE Details of index cases (sibs) with congenital adrenal hyperplasia.

\begin{tabular}{lcccc}
\hline & Male & Female & $\begin{array}{l}\text { Total } \\
\text { No }\end{array}$ & $\begin{array}{l}\text { \% of } \\
\text { total }\end{array}$ \\
\hline All index cases & 17 & 27 & 44 & 100 \\
Salt losers & 15 & 19 & 34 & 77 \\
$\quad$ Deaths & 4 & 5 & 9 & 20 \\
Non-salt losers & 2 & 8 & 10 & 23 \\
$\quad$ Deaths & 0 & 0 & 0 & 0 \\
\hline
\end{tabular}

the sample. ${ }^{13}$ There is now a question about the? reliability of the test for the prenatal diagnosis of certain variants of congenital adrenal hyperplasia $\stackrel{\rho}{-}$

In the eight pregnancies where the fetus was? known to be affected by 21-hydroxylase deficiency, $\frac{\mathrm{O}}{\overline{\mathrm{n}}}$ the concentration of $170 \mathrm{H}$-progesterone in amniotic fluid was clearly raised. The salt losing variant of congenital adrenal hyperplasia was a common factor in all these cases; this was confirmed in four infants delivered at term. The affected sibs of all fouraborted fetuses were also salt losers. Of the $55 \vec{\omega}$ pregnancies at risk for fetal 21-hydroxylase de- ficiency, $14.5 \%$ were affected compared to an expected incidence of $25 \%$ for an autosomal reces-iv sive disorder. However, in the larger group pre- + dicted to be unaffected and with normal infants at birth, there was one male non-salt loser proven to be $+\overrightarrow{+}$ affected at three months of age. In this instance theo proband was also a non-salt loser. However, the accepted dogma that the simple virilising or salte losing variant breeds true within a family is challenged by the recent observation of non-concor- dance for salt wasting in some HLA identical sibs. ${ }^{15}$ It is possible that simple virilising, late onset, and. cryptic variants of congenital adrenal hyperplasiad may only become recognised with continued follows up. The predominance of salt losers among cases detected prenatally in this and in two recentlyo reported studies ${ }^{11} 16$ emphasises that amniotic fluidळ $170 \mathrm{H}$-progesterone measurement is reliable only for $\overrightarrow{\vec{z}}$ the salt losing variant of congenital adrenalo hyperplasia.

There is close genetic linkage between HLA anc

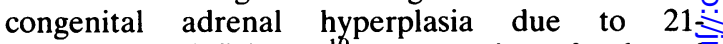
hydroxylase deficiency. ${ }^{10}$ HLA typing of culture $\overline{\bar{B}}$ amniotic cells and comparison with HLA antigens in the affected sib and parents has also been used for the prenatal diagnosis of fetal 21-hydroxylase deficiency. ${ }^{17}$ Although HLA typing was not useof systematically in this study, the concentration of $170 \mathrm{H}$-progesterone in amniotic fluid was marginally? raised in one pregnancy in which HLA analysis showed the fetus to be heterozygous for 21-hydroxy lase deficiency. The HLA types were confirmed aftero birth. HLA typing is technically more difficult and time consuming than amniotic fluid steroid analysis N Spurious results can occur due to antigen cross $\omega$ reactions, uninformative HLA genotypes, re combination between the HLA-A and B loci, an $\&$ occasionally from maternal cell contamination of amniotic cell cultures. Normal fetuses have mis:takenly been aborted on the basis of discordant results of amniotic steroid and HLA analysis. ${ }^{18}$ Anothero cause of error in the interpretation of HLA typing can? occur if the diagnosis of congenital adrenal hyper $\varrho$ plasia in the index case is incorrect. 
An alternative approach to prenatal diagnosis is by analysis of DNA isolated from chorionic villi. Using suitable cDNA probes which recognise sequences in the 21-hydroxylase gene complex, a structural gene deletion associated with the HLA-Bw47 haplotype ${ }^{19}$ and conversion of the 21-hydroxylase gene to an inactive or pseudogene, ${ }^{20}$ have recently been reported in patients with 21-hydroxylase deficiency. This allows the potential for prevention of virilisation in an affected female fetus by maternal administration of glucocorticoids in early gestation. However, present techniques of DNA analysis do not permit recognition of smaller gene deletions or point mutations which give rise to the various clinical phenotypes of congenital adrenal hyperplasia. ${ }^{21}$ It is likely that cDNA probes for the HLA-B and DR genes will be more informative for early prenatal diagnosis of 21-hydroxylase deficiency since these genes are highly polymorphic. ${ }^{22}$

It is uncommon for the parents of a child with congenital adrenal hyperplasia to request termination of another affected pregnancy. The unexpected birth of an infant with ambiguous genitalia or an infant ill from acute adrenal insufficiency are the usual reasons for the parents wishing to know the outcome in subsequent pregnancies. Of the index cases in this study, $77 \%$ were salt losers, many of whom were acutely ill before the correct diagnosis was made. A significant number $(20 \%$ of all index cases) had died in infancy, as had been reported in a previous genetic study of congenital adrenal hyperplasia in Wales. ${ }^{2.3}$ Measurement of amniotic fluid $170 \mathrm{H}$-progesterone concentrations during the second trimester reliably detects the fetus with salt losing 21-hydroxylase deficiency. The test is simple, rapid, and readily available and can predict the group of infants with congenital adrenal hyperplasia who are most at risk in early infancy.

Part of this work was supported by a grant from the Welsh Scheme for Health and Social Research. We thank the obstetricians, paediatricians, and medical geneticists who arranged to send us amniotic fluid samples for analysis. The manuscript was carefully prepared by Mrs Helen Gooding.

\section{References}

Hughes IA. Congenital and acquired disorders of the adrenal cortex. Clin Endocrinol Metab 1982:11:89-125.

2 Youssefnejadian E, David R. Early diagnosis of congenital adrenal hyperplasia by measurements of 17-hydroxyprogesterone. Clin Endocrinol 1975:4:451-4.

'Hughes IA. Riad-Fahmy D. Griffiths K. Plasma 170Hprogesterone concentrations in newborn infants. Arch Dis Child 1979:54:347-9.

+ Seron-Ferre M. Jaffe RB. The fetal adrenal gland. Ann Rev Physiol 1981:43:141-62.

${ }^{5}$ Frasier SD. Thorneycroft IH. Weiss BA. Horton R. Elevated amniotic fluid concentration of 17 $\alpha$-hydroxyprogesterone in congenital adrenal hyperplasia. J Pediatr 1975:86:310-2.

' Nagamani M. McDonough PG. Ellegood JO. Mahesh UB. Maternal and amniotic fluid 17a-hydroxyprogesterone levels during pregnancy: diagnosis of congenital adrenal hyperplasia in utero. Am J Obstet Gynecol 1978:130:791-4.

7 Hughes IA. Laurence KM. Antenatal diagnosis of congenital adrenal hyperplasia. Lancet 1979:ii:7-9.

$\times$ Pang S. Levine LS. Cederquist L. et al. Amniotic fluid concentrations of $\triangle^{5}$ and $\Delta^{+}$steroids in fetuses with congenital adrenal hyperplasia due to 21-hydroxylase deficiency and in anencephalic fetuses. J Clin Endocrinol Metab 1980:51:223-9.

"Hughes IA. Laurence KM. Prenatal diagnosis of congenital adrenal hyperplasia due to 21-hydroxylase deficiency by amniotic fluid steroids analysis. Prenatal Diagnosis 1982:2:97-1112.

11) New MI. Clinical and endocrinological aspects of 21hydroxylase deficiency. Ann NY Acad Sci 1985:458:1-27.

"Pang S. Pollack MS. Loo M. et al. Pitfalls of prenatal diagnosis of 21-hydroxylase deficiency congenital adrenal hyperplasia. Ann NY Acad Sci 1985:458:111-29.

12 Florensa E. Harrison R, Johnson M. Youssefnejadian E. Plasma 20a-dihydroxyprogesterone. progesterone and 17hydroxyprogesterone in normal human pregnancy. Acta Endocrinol (Kbh) 1977:86:634-40).

13 Dyas J, Read GF, Maulik TJ. Hughes IA. Riad-Fahmy D. A rapid assay for $170 \mathrm{H}$-progesterone in plasma, saliva and amniotic fluid using a magnetisable solid-phase antiserum. Ann Clin Biochem 1984:21:417-24.

it Tanimura T, Nelson T. Hollingsworth RR. Shepard TH. Weight standards for organs from early human fetuses. Anat Rec 1971:171:227-36.

15 Stoner E, Dimartino-Nardi J. Kuhnle U, Levine LS, Oberfield SE. New MI. Is salt-wasting in congenital adrenal hyperplasia due to the same gene as the fasciculata defect? Clin Endocrinol 1986:24:9-20.

16 Forest MG. Pitfalls in prenatal diagnosis of 21-hydroxylase deficiency by amniotic fluid steroid analysis? A six year experience in 102 pregnancies at risk. Ann NY Acad Sci 1985:458:130-47.

17 Pollack MS. Levine LS. Pang S, et al. Prenatal diagnosis of congenital adrenal hyperplasia (21-hydroxylase deficiency) by HLA typing. Lancet 1979;i:11(107-8.

${ }^{1 x}$ Forest MG, Betuel H, Couillin P, et al. Prenatal diagnosis of congenital adrenal hyperplasia (CAH) due to 21-hydroxylase deficiency by steroid analysis in the amniotic fluid of mid pregnancy: comparison with HLA typing in 17 pregnancies at risk for CAH. Prenatal Diagnosis 1981:1:197-207.

19) White PC. New MI, Dupont B. HLA-linked congenital adrenal hyperplasia results from a defective gene encoding a cytochrome P-450 specific for steroid 21-hydroxylation. Proc Natl Acad Sci USA 1984;81:7505-9.

20 Donohuc PA, Van Dop C. McClean RH. White PC, Jospe N, Migeon CJ. Gene conversion in salt-losing congenital adrenal hyperplasia with absent complement C4B protein. J Clin Endocrinol Metab 1986:62:995-1(0)2.

2 Rumsby G. Carroll MC, Porter RR, Grant DB, Hjelm M. Deletion of the steroid 21-hydroxylase and complement $\mathrm{C} 4$ genes in congenital adrenal hyperplasia. J Med Genet 1986:23:204-9.

22 New MI. Speiser PW. Genetics of adrenal steroid 21hydroxylase deficiency. Endocr Rev 1986:7:331-49.

2.3 Murtaza L. Sibert J, Hughes IA. Balfour IC. Congenital adrenal hyperplasia-a clinical and genetic survey. Are we detecting male salt-losers? Arch Dis Child 198();55:622-5.

Correspondence and requests for reprints to Dr I A Hughes, Department of Child Health, University of Wales College of Medicine, Heath Park, Cardiff CF4 4XN. 